Research Article

\title{
Association between hypertension in adolescents and the health risk factors of their parents: an epidemiological family study
}

\author{
Diego Giulliano Destro Christofaro, $\mathrm{PhD}^{\mathrm{a} \text {,* }}$, Arthur E. Mesas, $\mathrm{PhD}^{\mathrm{b}}$, \\ Raphael M. Ritti Dias, $\mathrm{PhD}^{\mathrm{c}}$, Rômulo A. Fernandes, $\mathrm{PhD}^{\mathrm{a}}$, Bruna T.C. Saraiva a , \\ Mariana R. Palma ${ }^{\mathrm{d}}$, Diego A.S. Silva, $\mathrm{PhD}^{\mathrm{e}}$, and Selma M. de Andrade, PhD ${ }^{\mathrm{b}}$ \\ ${ }^{a}$ Department of Physical Education, Universidade Estadual Paulista, São Paulo State University (Unesp), Presidente Prudente, \\ São Paulo, Brazil; \\ ${ }^{b}$ Department of Public Health, Universidade Estadual de Londrina, Londrina, Brazil; \\ ${ }^{c}$ Universidade Nove de Julho, São Paulo, São Paulo, Brazil; \\ ${ }^{d}$ UNESP Universidade Estadual Paulista, Presidente Prudente, São Paulo, Brazil; and \\ ${ }^{e}$ Department of Physical Education, Universidade Federal de Santa Catarina, Santa Catarina, Brazil
}

Manuscript received October 24, 2017 and accepted December 22, 2017

\begin{abstract}
Hypertension in adolescence may be a predictor of cardiovascular problems in adulthood. Therefore, verification of the factors associated with this condition in adolescence is important. The aim of this study was to analyze the relationship between hypertension in adolescents with hypertension and the sociodemographic characteristics and lifestyle of their parents. This study was conducted on 1231 adolescents, 1202 mothers, and 871 fathers. The blood pressure of the adolescents was measured with an oscillometric device. Details of parental hypertension, sociodemographic characteristics, and lifestyle were obtained by self-report. The prevalence of hypertension was higher among adolescents with older fathers and older mothers, with both parents reporting hypertension and with mothers who were overweight. In multivariable analysis, adolescents with older mothers $(\mathrm{OR}=2.36 ; 95 \%$ confidence interval $[\mathrm{CI}]=1.12-4.98)$, hypertensive mothers $(\mathrm{OR}=2.22$ $[95 \% \mathrm{CI}=1.26-3.89])$, and hypertensive fathers $(\mathrm{OR}=1.70[95 \% \mathrm{CI}=1.03-2.81])$ were more likely to have hypertension. In the analysis that considered clusters of health risk factors, higher risks of hypertension were observed in adolescents whose mothers had four or more aggregated risk factors $(\mathrm{OR}=2.53[95 \% \mathrm{CI}=1.11-5.74])$. In conclusion, there was a relationship between hypertension in adolescents and hypertension in their parents. However, an association between hypertension in adolescents and parental age and clusters of health risk factors was only observed for their mothers. J Am Soc Hypertens 2018;12(3):182-189. (c) 2018 American Society of Hypertension. All rights reserved.
\end{abstract}

Keywords: Blood pressure; fathers and mothers; youth.

\section{Introduction}

Hypertension is a relevant condition in childhood and adolescence. ${ }^{1,2}$ Adolescents with hypertension are more

Conflict of interest: None.

*Corresponding author: Diego Giulliano Destro Christofaro, $\mathrm{PhD}$, Department of Physical Education, Universidade Estadual Paulista São Paulo State University (Unesp), Rua Roberto Simonsen, 305, CEP: 19.060-900 Presidente Prudente, São Paulo, Brazil. Tel: (55) 18-3229-5388; Fax: (55) 18-3229-5710.

E-mail: diegochristofaro@yahoo.com.br likely to be hypertensive in adulthood, ${ }^{3,4}$ leading to various types of cardiovascular diseases.,

Parental hypertension has been associated with a higher risk of hypertension in their children. ${ }^{7}$ Although there is a link between genetic factors and the development of hypertension in adolescents, ${ }^{8}$ factors related to parental lifestyle may also contribute to this phenomenon. For example, Simonetti et al. ${ }^{9}$ observed significant associations between parental smoking and hypertension in children, even after adjusting for confounding factors such as body mass index, parental hypertension, and birth weight. Physical inactivity and sedentary behavior of parents may also contribute to 
the adoption of these behaviors by their children and adolescents, which, accompanied with unhealthy habits, ${ }^{10,11}$ increase the incidence of overweight and obesity and, ultimately, hypertension among adolescents. ${ }^{12}$

Despite these recognized relationships, little is known about whether parental lifestyle factors such as sedentary behavior, smoking, and alcohol consumption are related to increased blood pressure values in adolescents. Therefore, the aim of this study was to determine whether hypertension in adolescents is associated with parental lifestyle and other factors.

\section{Methods}

\section{Sample}

This study was conducted in the city of Londrina, southern Brazil. According to the Regional Center for Education of Londrina, there were 17,392 adolescents enrolled in high schools in 2010 , $55 \%$ females and $45 \%$ males (data provided by the Regional Center for Education of Londrina, Brazil). This study was conducted in adolescents attending the six largest public high schools in the downtown area. These schools were intentionally chosen because they receive students from all regions of the city and from different socioeconomic statuses. Adolescents aged 14-17 years from all classes in these six schools were invited to participate in this study, as were their parents or guardians. Adolescents who agreed to participate in the study received two consent forms-one for their parents or guardians to authorize the adolescents' participation in the study and one for the mothers and fathers to sign if they also agreed to participate in the study. Together with the consent forms, the questionnaires were sent to the parents to be answered at home. A total of 1495 students agreed to participate in the study, but only 1267 returned with their parents' consent form signed, allowing their participation in the study. Finally, 1231 adolescents participated in the evaluations. The exclusion criteria were (1) practice of physical activity within 24 hours prior to the blood pressure assessment; (2) the consumption of caffeinated beverages and/or chocolate the day prior to the assessment of the blood pressure measurement; and (3) the use of medication for controlling blood pressure. This study was approved by the ethics committee of the proponent research institution.

\section{Adolescents' Variables}

\section{Blood Pressure}

Systolic blood pressure (SBP) and diastolic blood pressure (DBP) were measured with an electronic device (Omrom HEM-742; Omron Corporation, Kyoto, Kansai, Japan) that was previously validated for pediatric populations. ${ }^{13}$ After 5 minutes of resting in a sitting position, two measures were taken on the right arm, with a 2-minute interval between them; the mean value was used. Values higher than the 95th percentile of the National High Blood Pressure Education Program cutoffs adjusted for age, gender, and height (NHBPEP 2004) were considered as hypertensive. ${ }^{14}$

\section{Anthropometry}

The adolescents were weighed using a digital scale with accuracy of $0.1 \mathrm{~kg}$; height was measured using a portable stadiometer with an accuracy of $1 \mathrm{~cm}$. Body mass index (BMI) was calculated by dividing weight by the square of the height. Adolescents were characterized as having or not having excess weight according to the cutoff points used by Cole et al. ${ }^{15}$

\section{Parent or Guardian Variables}

\section{Hypertension}

The parents' hypertension status was assessed by selfreport using the following questions: "Have you ever been diagnosed as hypertensive by a doctor?" or "Do you take any medication to control blood pressure?" Parents who responded yes for one of the questions were considered hypertensive.

\section{Sociodemographic Variables and Anthropometry}

The sociodemographic variables were age and parental schooling in years of study. These variables were divided into tertiles. The weight and height of the parents were assessed by self-report. From these values, BMI was calculated by dividing weight by the square of the height. Parents or guardians with a BMI value greater than $24.99 \mathrm{~kg} / \mathrm{m}^{2}$ were classified as overweight.

\section{Sedentary Behavior}

For parents or guardians, sedentary behavior considered the time spent using a computer and watching television in a week. The total hours of sedentary behavior were stratified into quartiles: those located in quartile 1 were classified as having low sedentary behavior, quartiles 2 and 3 as moderately sedentary and quartile 4 as high sedentary behavior.

\section{Physical Activity}

Physical activity (PA) was assessed using the questionnaire by Baecke et al. ${ }^{16}$ This questionnaire provides a total score based on the sum of different PA domains such as leisure activities and sports activities outside the school environment. PA during leisure time was determined from the information of the frequency regarding time spent by adults watching television, walking, or cycling during leisure time. Sports practice was determined by the intensity and length of time (number of hours per week) that the 
individual used to practice sports in the 12 months before the evaluation. This instrument has been tested and validated in Brazilian adults, ${ }^{17}$ and it has been validated against gold standard methods, such as the doubly labeled water method, for measuring physical activity. ${ }^{18}$

Initially, the score was calculated according to Baecke et al. ${ }^{16}$ The score was then divided into quartiles: parents located in quartile 1 were classified as inactive, quartiles 2 and 3 as moderately active and those in the highest quartiles as physically active.

\section{Alcohol Consumption}

Alcohol consumption was assessed by the questionnaire of the Brazilian Center for Psychotropic Drugs, ${ }^{19}$ which assesses the frequency and amount of drinks consumed. Parents or guardians who reported the consumption of more than 1-2 doses 1-2 days or more per week were classified as high consumers. The cutoff point adopted was that proposed by Moreira et al. ${ }^{20}$

\section{Smoking}

Smoking was assessed using the following question: Are you a smoker? If yes, how many cigarettes do you usually smoke per day? Adolescents and parents who reported being smokers and consumed at least one cigarette per day were classified as smokers.

\section{Statistics Analyses}

The association of hypertension in adolescents with sociodemographic characteristics and other variables of parents or guardians was evaluated using the chi-square test. All variables that were significant at $P \leq 20 \%$ were considered in the multivariate model performed by binary logistic regression. The adjusted multivariate analysis included the adolescents' gender, age, and BMI as confounding factors.

In the analysis of the association between hypertension in adolescents and hypertension and associations of health risk factors for parents, the variables sedentary behavior and physical activity were dichotomized, with health risk values equal to or greater than the 75th percentile for sedentary behavior and equal to or greater than the 25th percentile for physical activity. The associations of health risk factors for parents considered the following factors: hypertension, overweight, smoking, high consumption of alcoholic beverages, high sedentary behavior, and low physical activity. The analysis of associations created compared: (1) having no risk factors; (2) having one risk factor; (3) having two risk factors; (4) having three risk factors; and (5) having four or more risk factors.

The confidence interval (CI) was 95\%, and the statistical significance adopted was 5\%. The software used was SPSS, version 15.0.

\section{Results}

The study included 1231 adolescents (515 boys and 716 girls), 1202 mothers or female guardians, and 871 fathers or male guardians. The characteristics of the sample are shown in Table 1. The prevalence of hypertension was $12 \%, 19.7 \%$, and $23 \%$ in adolescents, mothers, and fathers, respectively.

Adolescents whose mothers were hypertensive had a higher mean SBP $(P=.046)$ and a higher mean DBP $(P=.002)$ compared with adolescents with normotensive mothers. Similar relationships were observed for adolescents whose fathers were hypertensive, as the mean SBP $(P=.006)$ and DBP $(P=.001)$ values were higher in adolescents with hypertensive fathers compared with adolescents whose fathers were normotensive.

There was a significant association between hypertension in adolescents with maternal age, BMI, and hypertension and with paternal age and hypertension. None of the parents' lifestyle characteristics were associated with hypertension in adolescents (Tables 2 and 3).

In the unadjusted analysis of the associations, hypertension in adolescents was significantly associated with maternal age, BMI, and hypertension and with paternal age and hypertension. In the adjusted analysis, after all variables were simultaneously inserted into the model, hypertension in adolescents remained associated with maternal age and with hypertension among both mothers and fathers (Table 4).

Table 1

Characterization of the sample

\begin{tabular}{lcc}
\hline Variables & Mean & $\begin{array}{l}\text { Standard Deviation } \\
(95 \% \mathrm{CI})\end{array}$ \\
\hline Adolescents & & \\
Age & 15.55 & 1.07 \\
Weight & 60.12 & 13.07 \\
Height & 166.70 & 9.18 \\
BMI & 21.55 & 3.89 \\
SBP & 114.97 & 11.38 \\
DBP & 64.84 & 7.80 \\
Hypertension (\%) & 12.00 & $(10.21-13.84)$ \\
Mothers & & \\
Age & 43.31 & 7.18 \\
Weight & 68.01 & 12.84 \\
Height & 161.36 & 6.47 \\
BMI & 26.10 & 4.66 \\
Hypertension $(\%)$ & 19.7 & $(17.47-21.97)$ \\
Fathers & & \\
Age & 45.76 & 7.45 \\
Weight & 82.16 & 14.50 \\
Height & 173.14 & 7.01 \\
BMI & 27.35 & 4.20 \\
Hypertension (\%) & 23.3 & $(20.50-26.11)$ \\
\hline
\end{tabular}

BMI, body mass index; CI, confidence interval; DBP, diastolic blood pressure; SBP, systolic blood pressure. 
Table 2

Hypertension in adolescents and the sociodemographic characteristics and risk factors for health in their parents or guardians

\begin{tabular}{|c|c|c|c|}
\hline Parents' Characteristics & Total (n) & HTN (\%) & $P$-Value \\
\hline \multicolumn{4}{|c|}{ Mother or female guardian } \\
\hline \multicolumn{4}{|l|}{ Age (y) } \\
\hline$\leq 40$ & 437 & 7.3 & \multirow[t]{3}{*}{$\leq .001$} \\
\hline$\overline{41-46}$ & 409 & 12.9 & \\
\hline$\geq 47$ & 356 & 15.7 & \\
\hline \multicolumn{4}{|l|}{ Education level (y) } \\
\hline$\leq 8$ & 288 & 12.8 & \multirow[t]{3}{*}{.669} \\
\hline $9-11$ & 520 & 9.8 & \\
\hline$\geq 12$ & 394 & 13.4 & \\
\hline \multicolumn{4}{|l|}{ Hypertension } \\
\hline Absence & 965 & 9.4 & \multirow[t]{2}{*}{$\leq .001$} \\
\hline Presence & 237 & 21.0 & \\
\hline \multicolumn{4}{|l|}{ BMI $\left(\mathrm{kg} / \mathrm{m}^{2}\right)$} \\
\hline$<25$ & 542 & 7.9 & \multirow[t]{2}{*}{$\leq .001$} \\
\hline$\geq 25$ & 660 & 14.8 & \\
\hline \multicolumn{4}{|l|}{ Father or male guardian } \\
\hline \multicolumn{4}{|l|}{ Age (y) } \\
\hline$\leq 43$ & 349 & 8.0 & \multirow[t]{3}{*}{.002} \\
\hline$\overline{44-47}$ & 193 & 15.5 & \\
\hline$\geq 48$ & 329 & 16.1 & \\
\hline \multicolumn{4}{|l|}{ Education level (y) } \\
\hline$\leq 8$ & 175 & 13.7 & \multirow[t]{3}{*}{.468} \\
\hline $9-11$ & 374 & 10.4 & \\
\hline$\geq 12$ & 322 & 14.9 & \\
\hline \multicolumn{4}{|l|}{ Hypertension } \\
\hline Absence & 668 & 10.4 & \multirow[t]{2}{*}{$\leq .001$} \\
\hline Presence & 203 & 20.1 & \\
\hline \multicolumn{4}{|l|}{ BMI $\left(\mathrm{kg} / \mathrm{m}^{2}\right)$} \\
\hline$<25$ & 256 & 13.3 & \multirow[t]{2}{*}{.744} \\
\hline$\geq 25$ & 615 & 12.5 & \\
\hline
\end{tabular}

BMI, body mass index; HTN, hypertension.

The associations between hypertension in adolescents and associations of health risk factors for parents revealed that when mothers had four or more risk factors simultaneously, adolescents were 2.5 times more likely to have hypertension compared with mothers with no risk factors (Table 5).

Adolescents who had only one hypertensive parent were approximately twice as likely to have this problem $(\mathrm{OR}=2.11[95 \% \mathrm{CI}=1.30-3.48])$. When both parents had hypertension, adolescents were four times more likely to have hypertension $(\mathrm{OR}=3.72[95 \% \mathrm{CI}=1.48-9.35])$.

\section{Discussion}

The main findings of this study were that hypertension in adolescents was associated with older maternal age and hypertension in both parents. Moreover, the largest number of associations of health risk factors for mothers had a significant relationship with hypertension in adolescents.

Higher blood pressure levels in adolescents were associated only with maternal age and not with paternal age. One
Table 3

Hypertension in adolescents and the lifestyle characteristics of their parents or guardians

\begin{tabular}{|c|c|c|c|}
\hline Parents' Lifestyle & Total (n) & $\operatorname{HTN}(\%)$ & $P$-Value \\
\hline \multicolumn{4}{|c|}{ Mother or female guardian } \\
\hline \multicolumn{4}{|c|}{ Sedentary behavior (h/wk) } \\
\hline$\leq 14$ & 322 & 11.8 & \multirow[t]{3}{*}{.649} \\
\hline $15-28$ & 564 & 10.9 & \\
\hline$\geq 29$ & 316 & 12.9 & \\
\hline \multicolumn{4}{|l|}{ Physical activity } \\
\hline Inactive & 369 & 13.0 & \multirow[t]{3}{*}{.886} \\
\hline Moderate & 522 & 10.1 & \\
\hline Active & 311 & 12.8 & \\
\hline \multicolumn{4}{|c|}{ High consumption of alcohol } \\
\hline Absence & 860 & 12.3 & \multirow[t]{2}{*}{.359} \\
\hline Presence & 342 & 10.2 & \\
\hline \multicolumn{4}{|l|}{ Smoking } \\
\hline Absence & 1051 & 11.3 & \multirow[t]{2}{*}{.278} \\
\hline Presence & 149 & 14.7 & \\
\hline \multicolumn{4}{|c|}{ Father or male guardian } \\
\hline \multicolumn{4}{|c|}{ Sedentary behavior (h/wk) } \\
\hline$\leq 14$ & 229 & 10.4 & \multirow[t]{3}{*}{.129} \\
\hline $15-29$ & 419 & 12.6 & \\
\hline$\geq 30$ & 223 & 15.2 & \\
\hline \multicolumn{4}{|l|}{ Physical activity } \\
\hline Inactive & 224 & 16.0 & \multirow[t]{3}{*}{.123} \\
\hline Moderate & 424 & 11.7 & \\
\hline Active & 223 & 11.2 & \\
\hline \multicolumn{4}{|c|}{ High consumption of alcohol } \\
\hline Absence & 345 & 11.8 & \multirow[t]{2}{*}{.608} \\
\hline Presence & 526 & 13.3 & \\
\hline \multicolumn{4}{|l|}{ Smoking } \\
\hline Absence & 714 & 13.1 & \multirow[t]{2}{*}{.524} \\
\hline Presence & 156 & 10.8 & \\
\hline
\end{tabular}

HTN, hypertension.

hypothesis is that this relationship may be determined by the older age of these mothers during pregnancy. Similar findings were observed in a study by Whincup et al., ${ }^{21}$ in which the age of mothers was related to hypertension in children. A possible explanation is that older mothers have an increased risk of having children with a low birth weight, ${ }^{22}$ which has been associated with hypertension in children. The occurrence of diabetes in children should also be considered. In a meta-analysis, Cardwell et al. ${ }^{23}$ observed that for each increase of 5 years in maternal age, the likelihood of the child having diabetes increased by $5 \%$. Subjects with diabetes have increased inflammatory markers related to endothelial dysfunction. ${ }^{24}$ Unfortunately, we did not collect data regarding the adolescents' diabetic status. Furthermore, the relationship between older parental age and BMI of adolescents (data not shown [there was a marginal relationship between maternal age and BMI in adolescence]) may also have contributed to this relationship since being overweight is commonly associated with hypertension. ${ }^{2,25}$ 
Table 4

Multivariable model analysis of the association between hypertension in adolescents' and parents' variables

\begin{tabular}{|c|c|c|c|c|c|c|}
\hline Variables & \multicolumn{3}{|c|}{ Unadjusted } & \multicolumn{3}{|c|}{ Adjusted } \\
\hline \multicolumn{7}{|l|}{ Mother's } \\
\hline$\leq 40$ & Ref & Ref & Ref & Ref & Ref & Ref \\
\hline $41-46$ & 1.88 & 1.18-2.98 & .007 & 2.50 & $1.28-4.89$ & .007 \\
\hline$\geq 47$ & 2.36 & 1.49-3.74 & .001 & 2.36 & $1.12-4.98$ & .024 \\
\hline$<25$ & Ref & Ref & Ref & Ref & Ref & Ref \\
\hline$\geq 25$ & 2.02 & 1.38-2.95 & $\leq .001$ & 1.04 & $0.63-1.74$ & .859 \\
\hline \multicolumn{7}{|l|}{ Hypertension } \\
\hline Absence & Ref & Ref & Ref & Ref & Ref & Ref \\
\hline Presence & 2.56 & $1.75-3.75$ & $\leq .001$ & 2.22 & $1.26-3.89$ & .005 \\
\hline \multicolumn{7}{|l|}{ Father's } \\
\hline$\geq 48$ & 2.20 & $1.35-3.57$ & .001 & 1.15 & $0.58-2.27$ & .687 \\
\hline \multicolumn{7}{|l|}{ Hypertension } \\
\hline Absence & Ref & Ref & Ref & Ref & Ref & Ref \\
\hline Presence & 2.16 & $1.41-3.30$ & $\leq .001$ & 1.70 & $1.03-2.81$ & .035 \\
\hline \multicolumn{7}{|c|}{ Sedentary behavior (h/wk) } \\
\hline$\leq 14$ & Ref & Ref & Ref & Ref & Ref & Ref \\
\hline $15-28$ & 1.23 & $0.74-2.06$ & .415 & 1.43 & $0.79-2.62$ & .235 \\
\hline$\geq 29$ & 1.53 & $0.87-2.68$ & .132 & 1.34 & $0.69-0.260$ & .381 \\
\hline \multicolumn{7}{|c|}{ Physical activity } \\
\hline Inactive & Ref & Ref & Ref & Ref & Ref & Ref \\
\hline Moderate & 0.69 & $0.43-1.10$ & .698 & .68 & $0.38-1.19$ & .177 \\
\hline
\end{tabular}

BMI, body mass index; CI, confidence interval.

Bold values are statistically significant.

Corroborating our findings regarding the association between parental and adolescents' hypertension, in a crosssectional study, Gomez-Garcia et al. ${ }^{26}$ found that children of parents with hypertension or diabetes were more likely to develop cardiovascular risk factors. These results were also observed by Kelishadi et al. $^{27}$ after evaluating the

Table 5

Association between hypertension in adolescents and clustering of health risk factors of their parents or guardians

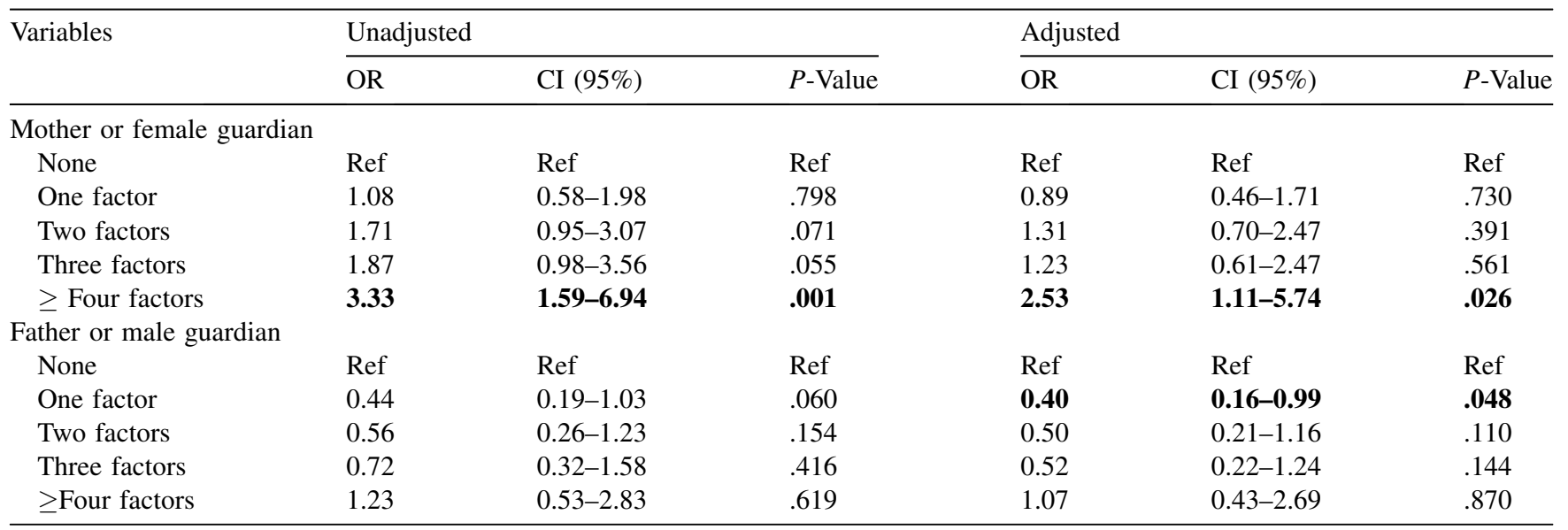

BMI, body mass index; CI, confidence interval.

Adjusted for sex, age and BMI of adolescents.

Bold values are statistically significant. 
relationship between hypertension in children and adolescents with hypertensive parents. In a cohort study conducted in 1948 in the city of Framingham in the United States, Lee et al. ${ }^{28}$ analyzed several biological markers and identified a correlation between SBP levels of parents and those of their children. These findings point to a significant genetic influence. Some genes transmitted from parents to their children can cause an increase in the renal absorption of salt in association with potassium deficiency, causing increased blood pressure. ${ }^{29}$ In addition, in our study, a multivariable analysis was performed comparing adolescents of parents without hypertension to those who had only one or both parents with hypertension and found an increased risk when both parents had hypertension.

Few studies have investigated whether parental lifestyle behaviors are associated with hypertension in adolescents. In the present study, no association was observed between lifestyle behaviors of parents and blood pressure levels in adolescents. In a study conducted by Watt et al., ${ }^{30}$ no association was found between parents with higher sodium excretion levels and higher blood pressure levels in children. Different findings were reported by Simonetti et al. ${ }^{9}$ in Germany, who found that the children of parents who smoked were more likely to have hypertension. The differences among results may be due to different methodologies. For example, this study used the average of two blood pressure measures and an oscillometric automatic device, whereas Simonetti et al. ${ }^{9}$ used three measurements and an aneroid device. In addition, the prevalence of smoking among parents in the study by Simonetti et al. ${ }^{9}$ was higher compared with that observed in our study: $28.5 \%$ of fathers and $20.7 \%$ of mothers reported being smokers in Germany; in our study, $17.9 \%$ of fathers and $12.4 \%$ of mothers reported this behavior. Another factor may be the age of the individuals. In the study by Simonetti et al., ${ }^{9}$ the population was composed of preschool children who generally spend more time with their parents and therefore are more likely to be exposed to smoke and subsequently to develop higher blood pressure levels. The population of our study was composed of adolescents, who are generally more independent and have other social relations mainly composed of their peers.

One of the novelties of this study was that it analyzes whether the association of parental health risk factors would increase the chance of hypertension in adolescents. This was not confirmed with fathers, but the adolescents of mothers with four or more associated risk factors were 2.5 times more likely to have hypertension. In addition to genetic factors, which could influence the occurrence of hypertension in adolescence, mainly due to some conditions during pregnancy, mothers tend to spend more time with their children than fathers and perhaps have more influence on their behavior such as sedentary lifestyle, physical inactivity, smoking, and alcohol consumption.

One of the limitations of this study is the self-reported assessment of hypertension among parents, which may contribute to its possible underestimation. The nonevaluation of diabetes in this study should be considered a limitation because parents' diabetes may be a risk factor for high blood pressure in children. Moreover, although we included adolescents' age, sex, and BMI in the statistical models as possible confounders, others such as physical activity, sedentary behavior, and alcohol consumption by adolescents were not included, and these behaviors may play an important role in the incidence of hypertension among young people. ${ }^{10,12}$ Another factor is the cross-sectional design of the study, a feature that does not allow us to infer a causal effect about the association of parental hypertension and higher blood pressure values in adolescents. The measurement of blood pressure in a single day is another factor to be considered as a limitation because it can overestimate the prevalence of hypertension. ${ }^{31}$ In addition, it was not possible to differentiate biological parents from guardians because the coordinator of the Education Department of the city where the study was conducted asked us not to inquire the adolescents about this situation to avoid possible constraints to the adolescents. Nevertheless, we believe that the majority of the adults who responded were the biological parents of the adolescents since our study was performed in a population whose socioeconomic status varies from average to low, which does not favor, for example, the hiring of maids. In addition, only approximately $4 \%$ of the male and female adults included in this study were older than 60 years, indicating they were potentially grandparents responsible for the adolescents. However, a positive aspect of this study is the large sample size, which is composed of adolescents, parents, or guardians, and the analyses exploring whether the lifestyle of these parents or guardians influence the blood pressure of adolescents. Another relevant aspect is the adjustment of statistical models for the main confounding variables in the analyses to verify whether some variables would modify associations in the final model.

In conclusion, this study showed that hypertension in adolescents is associated with hypertension in their parents and was related to maternal age and the presence of four or more health risk factors in mothers. The focus of health promotion activities should include the family as a whole, particularly mothers, thereby seeking to decrease the chances of hypertension in children.

\section{References}

1. Lee RLT, Lee PH, Sze DMY, Chien WT. Anthropometric profile of Hong Kong children and adolescents: the Wellness Population of Youth Study. J Am Soc Hypertens 2017;11(4):196-203.

2. Yang Y, Lau PW, Wang J, Dong B, Wu L, Quach B, et al. Associations among cardiorespiratory endurance, body mass index and blood pressure in Han Chinese 
children: results from the 2010 Chinese National Survey on Students' Constitution and Health. Hypertens Res 2016;39:799-804.

3. Juhola J, Oikonen M, Magnussen CG, Mikkilä V, Siitonen N, Jokinen E, et al. Childhood physical, environmental, and genetic predictors of adult hypertension: the Cardiovascular Risk in Young Finns Study. Circulation 2012;126:402-9.

4. Li Z, Snieder H, Harshfield GA, Treiber FA, Wang XA. 15-year longitudinal study on ambulatory blood pressure tracking from childhood to early adulthood. Hypertens Res 2009;32:404-10.

5. Nelson MJ, Ragland DR, Syme SL. Longitudinal prediction of adult blood pressure from juvenile blood pressure levels. Am J Epidemiol 1992;136:633-45.

6. Kuwahara E, Asakura K, Nishiwaki Y, Komatsu H, Nakazawa A, Ushiku H, et al. Steeper increases in body mass index during childhood correlate with blood pressure elevation in adolescence: a long-term followup study in a Japanese community. Hypertens Res 2014;37:179-84.

7. Yoo JE, Park HS. Relationship between parental hypertension and cardiometabolic risk factors in adolescents. J Clin Hypertens (Greenwich) 2017;19:678-83.

8. Snieder H, Hayward CS, Perks U, Kelly RP, Kelly PJ, Spector TD. Heritability of central systolic pressure augmentation. A twin study. Hypertension 2000;35: 574-9.

9. Simonetti GD, Schwertz R, Klett M, Hoffmann GF, Schaefer F, Wühl E. Determinants of blood pressure in preschool children: the role of parental smoking. Circulation 2011;123:292-8.

10. Ullrich-French SC, Power TG, Daratha KB, Bindler RC, Steele MM. Examination of adolescents' screen time and physical fitness as independent correlates of weight status and blood pressure. J Sports Sci 2010;28:1189-96.

11. Nosova EV, Yen P, Chong KC, Alley HF, Stock EO, Quinn A, et al. Short-term physical inactivity impairs vascular function. J Surg Res 2014;190:672-82.

12. Christofaro DG, De Andrade SM, Cardoso JR, Mesas AE, Codogno JS, Fernandes RA. High blood pressure and sedentary behavior in adolescents are associated even after controlling for confounding factors. Blood Press 2015;24:317-23.

13. Christofaro DG, Fernandes RA, Gerage AM, Alves MJ, Polito MD, Oliveira AR. Validation of the Omron HEM 742 blood pressure monitoring device in adolescents. Arq Bras Cardiol 2009;92:10-5.

14. National High Blood Pressure Education Program Working Group on High Blood Pressure in Children and Adolescents. The fourth report on the diagnosis, evaluation, and treatment of high blood pressure in children and adolescents. Pediatrics 2004;114: $555-76$.
15. Cole TJ, Bellizzi MC, Flegal KM, Dietz WH. Establishing a standard definition for child overweight and obesity worldwide: international survey. BMJ 2000; 320:1-6.

16. Baecke JAH, Burema J, Fruters JE. A short questionnaire for the measurement of habitual physical activity in epidemiological studies. Am J Clin Nutr 1982;36: 936-42.

17. Philippaerts RM, Westerterp KR, Lefevre J. Doubly labelled water validation of three physical activity questionnaires. Int J Sports Med 1999;20:284-9.

18. Florindo AA, Latorre Mdo R, Jaime PC, Tanaka T, Zerbini CA. Methodology to evaluation the habitual physical activity in men aged 50 years or more. Rev Saude Publica 2004;38:307-14.

19. Galduróz JCF, Noto AR, Nappo AS, Carlini EA. I Levantamento domiciliar nacional sobre o uso de drogas psicotrópicas: estudo envolvendo as 24 maiores cidades do estado de São Paulo. São Paulo: CEBRID/Unifesp; 1999.

20. Moreira LB, Fuchs FD, Moraes RS, Bredemeier M, Cardozo S, Fuchs SC, et al. Alcoholic beverage consumption and associated factors in Porto Alegre, a southern Brazilian city: a population-based survey. J Stud Alcohol 1996;57:253-9.

21. Whincup PH, Cook DG, Shaper AG. Early influences on blood pressure: a study of children aged 5-7 years. BMJ 1989;299:587-91.

22. Heffner LJ. Advanced maternal age-how old is too old? N Engl J Med 2004;351:1927-9.

23. Cardwell CR, Stene LC, Joner G, Bulsara MK, Cinek O, Rosenbauer J, et al. Maternal age at birth and childhood type 1 diabetes: a pooled analysis of 30 observational studies. Diabetes 2010;59:486-94.

24. Machnica L, Deja G, Polanska J, Jarosz-Chobot P. Blood pressure disturbances and endothelial dysfunction markers in children and adolescents with type 1 diabetes. Atherosclerosis 2014;237:129-34.

25. Fernandes RA, Christofaro DG, Buonani C, Monteriro HL, Cardoso JR, Freitas IF Jr, et al. Performance of body fat and body mass index cutoffs in elevated blood pressure screening among male children and adolescents. Hypertens Res 2011;34:963-7.

26. Gómez-García A, Rangel-García L, Alvarez-Aguilar C. A cross-sectional study to assess cardiovascular risk in the children of parents with diabetes mellitus or arterial hypertension. Semergen 2012;38:278-84.

27. Kelishadi R, Hashemipour M, Bashardoost N. Blood pressure in children of hypertensive and normotensive parents. Indian Pediatr 2004;41:73-7.

28. Lee KE, Klein BE, Klein R. Familial aggregation of components of the multiple metabolic syndrome in the Framingham Heart and Offspring Cohorts: Genetic Analysis Workshop Problem 1. BMC Genet 2003; 1(4 Suppl):S94. 
29. Nabel E. Cardiovascular disease. N Engl J Med 2003; 349:60-72.

30. Watt GC, Foy CJ, Hart JT. Comparison of blood pressure, sodium intake, and other variables in offspring with and without a family history of high blood pressure. Lancet 1983;1(8336):1245-8.
31. de Oliveira LMFT, da Silva AO, Diniz PRB, Farah BQ, Pirauá ALT, de Lima Neto AJ, et al. The number of visits and blood pressure measurements influence the prevalence of high blood pressure in adolescents. J Am Soc Hypertens 2017;11(6): 343-9. 